\title{
Energia incorporada na fase de pré-uso: comparação entre lajes steel deck e maciças
}

\author{
Embodied energy in pre-use: comparison between steel \\ deck- and massive slabs
}

\section{Rachel de Sousa Santos}

\section{Resumo}

A

industrialização vem ganhando espaço como solução forte de economia e possibilita reduzir o consumo de materiais, recursos humanos, energéticos, temporais e financeiros em escalas diversas. Com isso, novas tecnologias vêm surgindo, como a laje steel deck, assim como estudos mais detalhados necessários para se verificar o consumo de energia e seu impacto no meio ambiente, além de comparação com sistemas tradicionais. Nesse contexto, este trabalho tem a finalidade de comparar dois tipos de sistemas de laje (maciça e steel deck) a partir de suas energias incorporadas na fase de pré-uso, que engloba extração da matéria-prima, produção dos materiais e componentes, transporte até a obra e execução. A metodologia foi desenvolvida a partir de uma dissertação de mestrado que dimensionou esses dois tipos de sistemas, tornando possível calcular as massas para os materiais e componentes mais relevantes. Adotaram-se as energias incorporadas (MJ/kg) com base em dados coletados da literatura. Como conclusão, os sistemas diferiram em energia incorporada na faixa dos 13\%, mostrando que a energia incorporada da laje steel deck foi superior à maciça devido ao aço apresentar um elevado grau de energia para sua extração e produção.

Palavras-chave: Avaliação do ciclo de vida energético. Energia incorporada. Laje maciça. Laje steel deck.

\begin{abstract}
Industrialisation has become a powerful economic solution: it allows the reduction of material consumption, human resources, energy, time and financial resources to varying extents. Hence, new technologies arise, such as the steel deck slab system, and also the need of new, detailed studies analysing energy consumption and environmental impact, as well comparisons with traditional systems. The goal of this study is to compare two types of slab systems (concreteand steel deck systems) with regards to their incorporated energy in the pre-use phase, which includes raw material extraction, components production, transportation to the site and execution. The methodology applied had already been used in other studies that broke down the systems, allowing the calculation of mass and energy at lower levels of the most important components. The incorporated energy rates used were also from earlier studies. This study

concluded that the systems differ in energy by $13 \%$, and showed that the incorporated energy in steel deck slab systems is higher than that of massive slabs due to the steel component, which presents high levels of energy extraction and production.

Keywords: Life cycle energy. Embodied energy. Steel deck. Concrete slab.
\end{abstract}

${ }^{1}$ Rachel de Sousa Santos

${ }^{1}$ Universidade de Brasília Brasília - DF - Brasil

Recebido em 03/07/18

Aceito em 04/09/18 


\section{Introdução}

Nas últimas décadas, a preocupação com o meio ambiente vem se ampliando. Isso pode ser explicado pelos atuais padrões de produção que impactam negativamente no meio ambiente, gerando problemas como o acúmulo de lixo, o aquecimento global e a modificação de ecossistemas (SPOSTO; PAULSEN, 2014).

Diante das mudanças climáticas e servindo como alerta para a população sobre as crises social e ambiental associadas a essas mudanças, emergiu o conceito de desenvolvimento sustentável. De acordo com o relatório Brundtland, esse conceito refere-se à capacidade das gerações atuais suprirem suas necessidades sem comprometerem as futuras de fazerem o mesmo (BRUNDTLAND et al., 1987).

Na literatura são encontradas diferentes definições para o desenvolvimento sustentável, mas todas convergem para a equidade das gerações, devendo a tomada de decisão ter como base as implicações sociais, ambientais e econômicas, tripé da sustentabilidade (CASTANHEIRA; GOUVEIA, 2004). O princípio social diz respeito ao capital humano, considerando as pessoas e suas condições de vida; o ambiental trata do capital natural, que se refere aos recursos naturais e a forma como estes são utilizados pela sociedade; e o econômico está relacionado com a produção, a distribuição e o consumo dos bens e serviços e leva em consideração os outros dois princípios (LABORATÓRIO..., 2012).

Assim, para que haja um avanço na sustentabilidade é importante a mitigação do uso dos recursos escassos e das emissões de gases nocivos. Abordando o consumo de energia pelo viés da sustentabilidade, constata-se que a demanda por recursos energéticos tem sido uma das principais causas do desequilíbrio ambiental mundial (PEDROSO, 2015). Dentre os segmentos responsáveis por esse desequilíbrio está a construção civil, uma grande consumidora de recursos (água, materiais e energia) e geradora de resíduos e emissões prejudiciais ao meio ambiente (SHARMA et al., 2011).

As construções desempenham um papel importante no consumo de energia em todo o mundo (LOTTEAU; LOUBET; SONNEMANN, 2017). Os edifícios utilizam energia ao longo de toda sua vida, desde a construção até a demolição, demandando energia tanto de forma direta quanto indireta. A energia direta é usada para a construção, operação, manutenção e demolição de um edifício, ao passo que a indireta é consumida para a produção das matérias-primas utilizadas nas instalações técnicas e construções (ALSHAMRANI, 2015; DIXIT, 2017).

Para medir e avaliar os impactos que um material ou produto geram sobre a saúde humana, o meio ambiente e as reservas de recursos naturais ao longo de toda a sua vida útil, procedimentos sistemáticos estão sendo utilizados (LOBO, 2010). Com isso, na busca da origem e interpretação dos impactos gerados a partir da produção de bens e serviços foi desenvolvida a avaliação do ciclo de vida (ACV) (ABNT, 2009a).

Além de métodos para a avaliação de impactos, a busca pela industrialização na construção civil é hoje uma tendência mundial, pois visa otimizar o uso de recursos materiais, humanos, organizacionais, energéticos, tecnológicos, temporais e financeiros disponíveis em todas as fases da construção (SABBATINI, 1989).

Com o desenvolvimento de diversos sistemas estruturais e construtivos e com a busca por usufruir das vantagens de cada material, surgiu o sistema formado por elementos mistos de aço e concreto (laje steel deck) (LIMA, 2009).

No Brasil, quer a estrutura de múltiplos pavimentos seja em concreto ou em estrutura metálica, a laje é usualmente de concreto. Sua execução utiliza um processo construtivo artesanal (fôrmas de madeira e escoramento), o que reduz a velocidade da construção. No entanto, ainda que este seja o sistema mais difundido no país, existem outras tecnologias, como as lajes mistas de aço e concreto (steel deck), que têm por finalidade racionalizar os processos construtivos e vencer prazos e custos da obra (LIMA, 2009).

O objetivo deste artigo consiste na avaliação do ciclo de vida energético (ACVE) das lajes mistas tipo steel deck e das lajes maciças convencionais para um trecho de um pavimento durante a fase de pré-uso.

\section{Referencial teórico}

\section{Sistema de lajes}

O sistema de laje maciça apresenta seção homogênea na qual toda a espessura é composta de concreto, armaduras longitudinais de flexão e eventualmente armaduras transversais. Para a sua execução são utilizadas fôrmas e escoras que sustentam a estrutura de concreto armado durante 0 processo de cura, até que o concreto adquira resistência própria (LIMA, 2009).

Já o sistema de laje com fôrma incorporada é composto por uma chapa trapezoidal de aço 
galvanizado e uma camada de concreto (Figura 1). A chapa de aço atua como armadura positiva, e para os momentos fletores negativos devem ser previstas armaduras de reforço. Além disso, essas chapas funcionam como fôrmas e têm por finalidade suportar e conter o concreto e servir de suporte para as demais cargas permanentes e sobrecargas de construção durante a fase de cura do concreto. Após a cura do concreto, as fôrmas ficam incorporadas a ele, atuando como armadura total ou parcial de tração, constituindo assim uma laje mista. Vale ressaltar que a não utilização de escoramento é válida para vãos de até $3 \mathrm{~m}$ de comprimento (LIMA, 2009).

\section{Avaliação do Ciclo de Vida Energético (ACVE)}

A gestão ambiental moderna se baseia no ciclo de vida do produto e tem como principal técnica a ACV. Esta técnica é baseada nas normas NBR ISO 14040 (ABNT, 2009a) e NBR ISO 14044 (ABNT, 2009b), que propõem a elaboração de um estudo em quatro fases: definição do objetivo e escopo, análise do inventário, avaliação de impacto e interpretação. Os princípios, as estruturas e as metodologias apresentados pelas normas servem de subsídio para a melhoria de produtos e serviços avaliados, bem como para o planejamento estratégico, marketing e elaboração de políticas públicas (SPOSTO; PAULSEN, 2014).

A ACV é uma ferramenta cuja finalidade é avaliar quantitativamente um material utilizado, os fluxos de energia e os impactos ambientais dos produtos, analisando sistematicamente o impacto de cada material ao longo de toda a vida útil de um produto (do berço ao túmulo, isto é, desde extração, processamento, fabricação até uso e disposição) (CHASTAS et al., 2017; GOUVEIA, 2012). Em outras palavras, a ACV consiste na mensuração das entradas (consumo de matéria-prima e energia) e saídas (emissões, resíduos, efluentes, etc.) ao longo do ciclo de vida de um produto ou um processo, o que permite, assim, a avaliação do seu desempenho ambiental (SHARMA et al., 2011).

Devido à complexidade do levantamento de dados para o inventário, em que os impactos são muito abrangentes, e ao fato de que as edificações normalmente incluem uma grande quantidade de materiais, diversos estudos (CHAU; LEUNG; NG, 2015; MILLER; DOH; MULVEY, 2015; RAUF; CRAWFORD, 2015) têm demonstrado que a simplificação da análise focalizando apenas a energia como indicador para impacto ambiental é eficaz.

De acordo com Sposto e Paulsen (2014), a produção de energia causa um grande desequilíbrio ambiental. Ela gera a maior parte das emissões e o uso da maioria dos recursos não renováveis.

A ACVE é uma abordagem que explica todas as entradas de energia em um edifício durante o seu ciclo de vida. Os limites do sistema desta análise incluem o uso da energia em três fases: pré-uso, uso e pós-uso (Quadro 1) (PAULSEN; SPOSTO, 2013).

\section{Figura 1 - Componentes da laje steel deck}

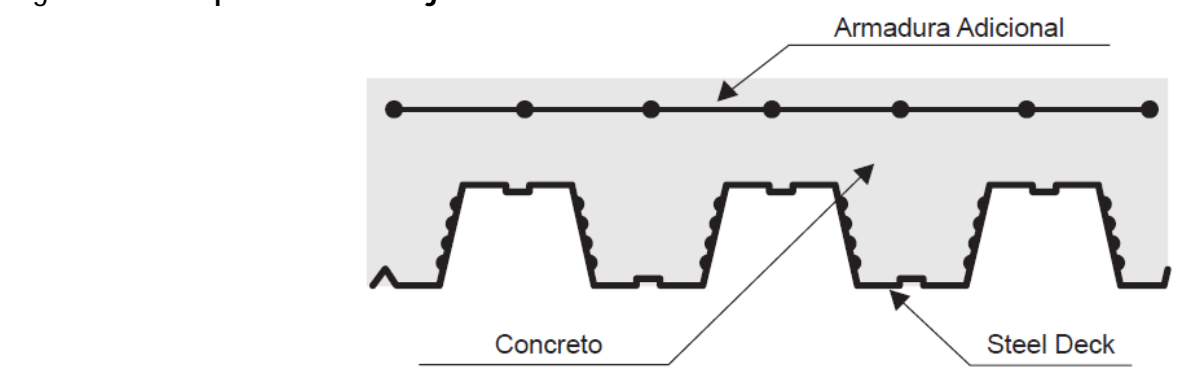

Fonte: METFORM (2017).

Quadro 1 - Fases do inventário de uma ACVE

\begin{tabular}{|l|c|l|l|}
\hline \multicolumn{1}{|c|}{ Fase } & Estágio & \multicolumn{1}{|c|}{ Símbolo } & \multicolumn{1}{c|}{ Descrição } \\
\hline Pré-uso & 1 & $\mathrm{E}_{\text {ext }}$ & Extração da matéria-prima \\
\hline & 2 & $\mathrm{E}_{\text {prod }}$ & Fabricação de materiais e componentes \\
\hline & 3 & $\mathrm{E}_{\mathrm{tr}, \mathrm{mat}}$ & Transporte até a obra \\
\hline & 4 & $\mathrm{E}_{\mathrm{exe}}$ & Execução \\
\hline Uso & 5 & $\mathrm{E}_{\mathrm{man}}$ & Manutenção, substituição de materiais \\
\hline Pós-uso & 6 & $\mathrm{E}_{\mathrm{op}}$ & Energia operacional \\
\hline & 7 & $\mathrm{E}_{\mathrm{dem}}$ & Demolição de construção e materiais \\
\hline
\end{tabular}


Em termos de energia, a fase de pré-uso considera a energia incorporada inicial, em que o conjunto dos insumos energéticos, diretos e indiretos, é utilizado para erguer a edificação.

Durante a vida útil da edificação, quando se faz necessário o uso de equipamentos para suprir as necessidades como cocção, climatização e iluminação, por exemplo, além de serem necessárias reformas em função da depreciação de materiais ou por função estética, a fase de uso utiliza as energias operacional e de manutenção. Por fim, a fase de pós-uso consome a energia de desconstrução, quando a energia é utilizada para o descarte, deposição ou reciclagem (TAVARES, 2006).

Vale ressaltar, no entanto, que a proposta de uma ACVE não é substituir o método de uma ACV, e sim facilitar tomadas de decisões sobre a eficiência energética e os impactos associados, tal como controlar as emissões e reduzir o consumo de energia primária nos edifícios.

\section{Método}

A metodologia aplicada neste artigo foi do tipo quantitativa e empregou o uso de um estudo de caso baseado na dissertação de Lima (2009) sobre sistemas de lajes em edifício do tipo steel frame. A partir deste trabalho foram realizadas as ACVEs para os dois tipos de laje: convencional maciça e steel deck para a fase de pré-uso.

\section{Descrição do estudo de caso}

A ACVE foi empregada para comparar a energia incorporada na fase de pré-uso das lajes de steel deck e maciça. Embora os diferentes tipos de lajes influenciem no dimensionamento estrutural das edificações, consideraram-se apenas as lajes dimensionadas para um trecho de um pavimento do estudo de caso 1 de Lima (2009), cujas áreas são iguais a $44,05 \mathrm{~m}^{2}$.

Para as lajes maciças adotou-se a resistência característica do concreto como fck $=25 \mathrm{MPa}$, as armaduras de aço CA-50 com cobrimento de $2 \mathrm{~cm}$, fôrmas de madeira com chapas resinadas com espessura igual a $12 \mathrm{~mm}$ e duas linhas de escoramento por vão de laje (Figura 2).

Para as lajes do tipo steel deck a resistência característica do concreto adotada foi de $25 \mathrm{MPa}$, a chapa de aço galvanizado utilizada foi a trapezoidal A 653 (AMERICAN..., 2018) Grau 40 (ZAR-280) e a armação foi de aço CA-60 (tela para fissuração Q-75) (Figura 3). A altura da laje foi de $14 \mathrm{~cm}$.

\section{Cálculo da energia incorporada nas lajes}

Para o cálculo de energia incorporada foi considerada apenas a fase de pré-uso. Foram analisados todos os seus quatro estágios: extração da matéria-prima, produção de materiais e componentes, transporte até a obra e execução da obra. No último estágio foram considerados apenas os desperdícios dos materiais.

No que diz respeito aos materiais e componentes, consideraram-se apenas os mais expressivos para a execução das lajes. Para a laje maciça levou-se em conta o concreto, as fôrmas de chapa resinada, o aço e o escoramento. Já para a laje steel deck foram analisados o concreto, a chapa de aço galvanizada e a tela de aço.

\section{Figura 2 - Plano de vigas para lajes maciças}

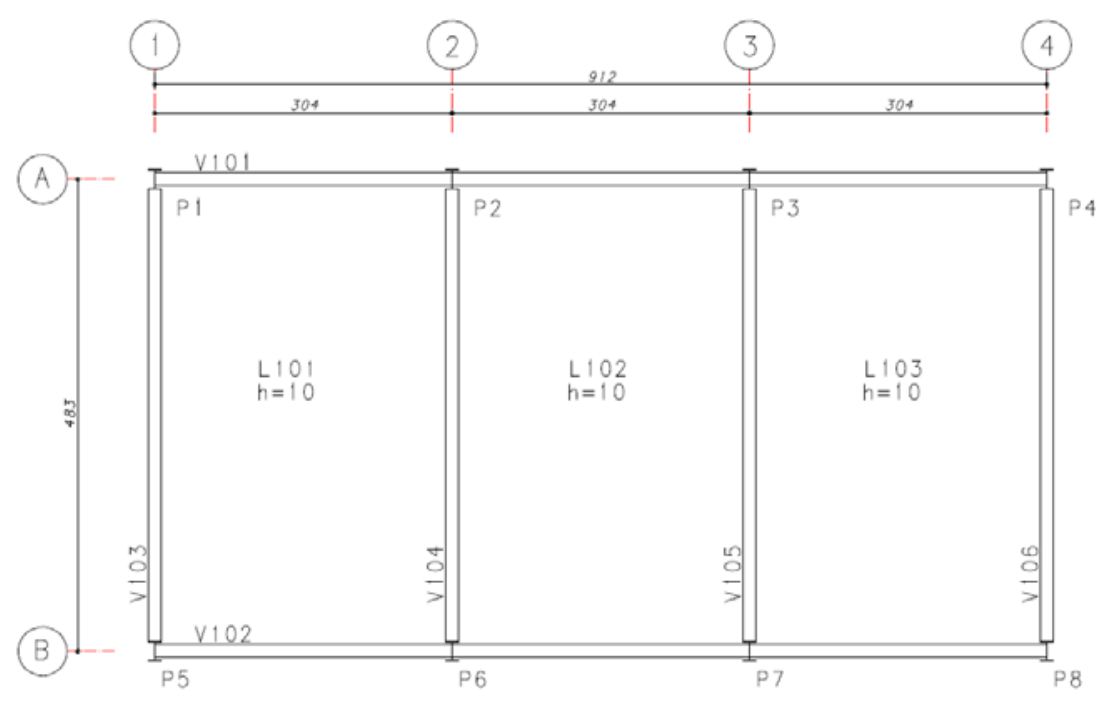

Fonte: Lima (2009). 
Figura 3 - Plano de vigas para lajes steel deck

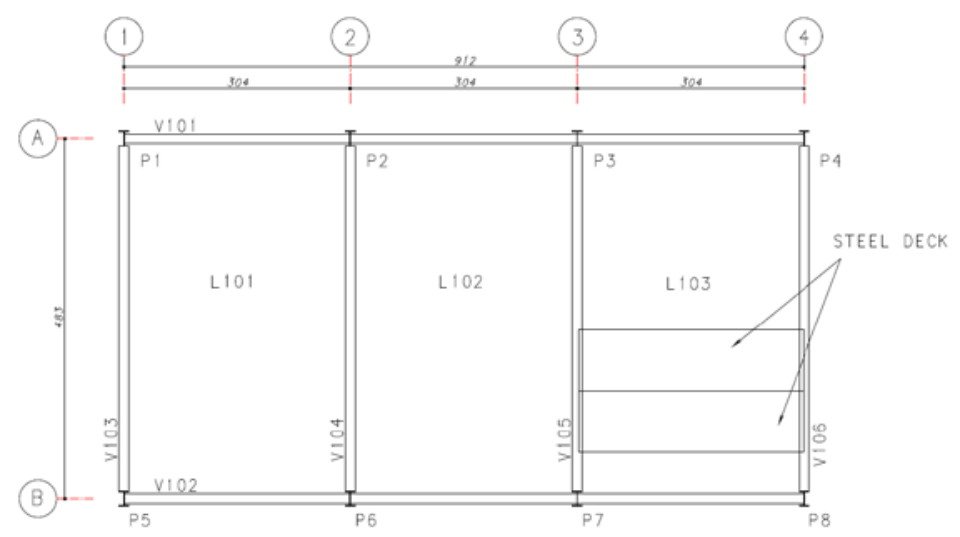

Fonte: Lima (2009).

Em função da impossibilidade de definir uma distância de transporte para todos os materiais analisados, adotou-se, conforme Tavares (2006), uma distância fixa de $80 \mathrm{~km}$. Além disso, essa distância também foi fixada com o intuito de obter energias incorporadas para os materiais saindo do mesmo local, sem que localidades próximas prejudicassem a análise e servissem apenas para a região estudada.

Com o pressuposto de que todos os transportes são realizados por caminhão, sobre a distância foi aplicado o índice de consumo energético de 1,62 $\mathrm{MJ} / \mathrm{t} / \mathrm{km}$, resultando no índice simplificado de 0,13 $\mathrm{MJ} / \mathrm{kg}$ de produto transportado. Ainda segundo o autor, os materiais desperdiçados têm o dobro da distância de transporte, levando assim ao índice de $0,26 \mathrm{MJ} / \mathrm{kg}$.

Para o estágio de execução não foi considerada a energia oriunda da mão de obra e dos equipamentos devido à falta de dados para permitir o cálculo. Segundo Tavares (2006), os conteúdos energéticos de obra são pouco estudados no Brasil e o consumo direto com equipamentos corresponde a $0,27 \%$ da energia incorporada nos materiais de construção, enquanto os desperdícios podem somar até $25 \%$. Sendo assim, neste estágio foram analisados apenas os percentuais de desperdícios adotados nas Tabelas de Composições de Preços para Orçamentos (PINI, 2008) e em Tavares (2006).

Como a unidade funcional é em metros quadrados e as lajes têm a mesma área $\left(44,05 \mathrm{~m}^{2}\right)$, suas energias incorporadas foram calculadas em $\mathrm{MJ} / \mathrm{m}^{2}$ para permitir comparações futuras com outros estudos de caso.

Conforme o cenário de estudo, a Tabela 1 apresenta os valores obtidos para as massas, energias incorporadas, perdas e transportes dos materiais.

\section{Resultados e discussões}

A partir da metodologia aplicada obtiveram-se as energias incorporadas calculadas durante a fase de pré-uso para os principais componentes dos dois tipos de sistemas analisados (Tabela 2). Os dados mostram que a laje que tem maior energia incorporada total na fase de pré-uso é a do tipo steel deck: 31.205,86 MJ, contra 27.588,66 MJ da laje maciça.

Os resultados demonstraram que a laje steel deck consome $13 \%$ a mais de energia durante a fase de pré-uso do que a laje convencional. A diferença entre energias dos sistemas se deve à chapa de aço galvanizada e à tela de aço do steel deck, pois o concreto, mesmo sendo um material que exige maior gasto energético, não foi o causador dessa disparidade, visto que as suas quantidades foram praticamente as mesmas nos dois tipos.

De acordo com a tabela abaixo, observa-se que na laje maciça o maior responsável pela energia embutida é o concreto C25, que representa 68,15\% do total da energia no sistema. Já os materiais de madeira são os que apresentam a menor quantidade de energia, 9,01\%. A laje steel deck também tem no concreto fck = $25 \mathrm{MPa}$ o seu maior incorporador de energia (57,19\%). No entanto, devido ao fato de o sistema apresentar em sua maioria aço e concreto, o aço é responsável pelos outros 42,81\%, o que é muito maior quando comparado com o sistema de laje maciça, no qual o aço representa apenas $22,83 \%$.

Cabeza et al. (2014) constataram que o aço influencia fortemente o aumento de energia incorporada durante as fases do ciclo de vida dos edifícios. Reddy e Jagadish (2003), durante a produção dos materiais, observaram que o aço apresenta maior gasto energético em seus processos, sendo o responsável pela elevação de energia incorporada na execução de edifícios. 
Tabela 1 - Dados sobre os materiais e componentes estudados

\begin{tabular}{|c|c|c|c|c|c|}
\hline \multicolumn{6}{|c|}{ Laje maciça } \\
\hline Materiais e componentes & Massa (kg) & EI (MJ/kg) & Fonte & $\begin{array}{c}\text { Perdas } \\
(\%)\end{array}$ & $\begin{array}{c}\text { Transporte } \\
\text { (km) }\end{array}$ \\
\hline Fôrma chapa resinada $12 \mathrm{~mm}$ & 239,25 & 8,00 & Tavares, 2006 & 15 & 80 \\
\hline Armação aço CA-50 & 190,00 & 30,00 & Tavares, 2006 & 10 & 80 \\
\hline Concreto usinado C25 & $9.912,00$ & 1,60 & Sposto, 2014 & 9 & 80 \\
\hline Escoramento de madeira & 330,00 & 0,50 & Tavares, 2006 & 15 & 80 \\
\hline \multicolumn{6}{|c|}{ Laje steel deck } \\
\hline Materiais e Componentes & Massa (kg) & EI (MJ/kg) & Fonte & $\begin{array}{c}\text { Perdas } \\
(\%)\end{array}$ & $\begin{array}{l}\text { Transporte } \\
\text { (km) }\end{array}$ \\
\hline Estrutura metálica & 313,50 & 33,80 & Tavares, 2006 & 10 & 80 \\
\hline Concreto usinado C25 & $9.408,00$ & 1,60 & Tavares, 2006 & 9 & 80 \\
\hline $\begin{array}{l}\text { Armação aço CA-60 (tela p/ } \\
\text { fiss. - Q -75) }\end{array}$ & 49,91 & 30,00 & Sposto, 2014 & 10 & 80 \\
\hline
\end{tabular}

Tabela 2 - Energia Incorporada dos principais componentes dos sistemas de estudo durante os estágios da fase de pré-uso

\begin{tabular}{|c|c|c|c|c|c|c|}
\hline \multicolumn{7}{|c|}{ Laje maciça convencional } \\
\hline Componentes & $\begin{array}{l}\text { EI Insumo } \\
\text { (MJ) }\end{array}$ & $\begin{array}{c}\text { EI Desp. } \\
\text { (MJ) }\end{array}$ & $\begin{array}{c}\text { EI } \\
\text { Transp. } \\
\text { (MJ) }\end{array}$ & $\begin{array}{c}\text { EI Transp. } \\
\text { Desp. } \\
\text { (MJ) }\end{array}$ & $\begin{array}{c}\text { EI Total } \\
\text { (MJ) }\end{array}$ & $\begin{array}{c}\text { EI } \\
\left(\mathbf{M J} / \mathbf{m}^{2}\right)\end{array}$ \\
\hline $\begin{array}{l}\text { Fôrma chapa resinada } 12 \\
\text { mm }\end{array}$ & $1.914,00$ & 287,10 & 31,01 & 9,30 & $2.241,41$ & 50,88 \\
\hline Armação aço CA-50 & $5.700,00$ & 570,00 & 24,62 & 4,92 & $6.299,55$ & 143,01 \\
\hline Concreto usinado C25 & $15.859,20$ & $1.427,33$ & $1.284,60$ & 231,23 & $18.802,35$ & 426,84 \\
\hline Escoramento de madeira & 165,00 & 24,75 & 42,77 & 12,83 & 245,35 & 5,57 \\
\hline Total & $23.638,20$ & $2.309,18$ & $1.382,99$ & 258,28 & $27.588,66$ & 626,30 \\
\hline \multicolumn{7}{|c|}{ Laje steel deck } \\
\hline Estrutura metálica & $10.596,30$ & $1.059,63$ & 40,63 & 8,13 & $11.704,69$ & 265,71 \\
\hline Concreto usinado C25 & $15.052,80$ & $1.354,75$ & $1.219,28$ & 219,47 & $17.846,30$ & 405,14 \\
\hline $\begin{array}{l}\text { Armação aço CA-60 } \\
\text { (tela p/ fiss. - Q -75) }\end{array}$ & $1.497,38$ & 149,74 & 6,47 & 1,29 & $1.654,87$ & 37,57 \\
\hline Total & $27.146,48$ & $2.564,12$ & $1.266,38$ & 228,89 & $31.205,86$ & 708,42 \\
\hline
\end{tabular}

O alto valor de energia incorporada pelo aço pode ser explicado pelo fato de os materiais metálicos consumirem muita energia desde a sua extração da natureza até a sua redução e fabricação na forma final de uso (SILVA; SILVA, 2015).

Além dos sistemas e componentes, também foram analisados os estágios que mais consumiram energia (Figuras 4 e 5).

Os gráficos que seguem permitem aferir que o estágio que mais consumiu energia foi justamente o de extração e de produção dos materiais, sendo praticamente o mesmo consumo para ambos os sistemas. Este índice elevado se deve, embora não exclusivamente, à estrutura de consumo de energia como, por exemplo, aquecimento, iluminação, condicionamento de materiais, etc.; e à eficiência energética para a fabricação dos materiais.
O estudo de Tavares (2006) observou que nesta fase também houve a predominância de energia consumida na fabricação dos materiais e que o desperdício superou o transporte, achados que constam também neste trabalho.

Ainda de acordo com as Figuras 4 e 5, verifica-se que os transportes tiveram seus valores bem próximos para ambas as lajes (5\%-6\%). Isso pode ser explicado devido a uma condição inicialmente adotada, em que todas as distâncias foram as mesmas por conta da dificuldade de obtenção de dados mais precisos para o presente estudo. No entanto, vale ressaltar que este estágio é de grande valia para a análise energética e que quanto maior a distância e a carga transportada, maior será a energia incorporada, além de maior emissão de $\mathrm{CO}_{2}$ (SPOSTO; CALDAS; NETO, 2016). 
Por fim, a análise da energia incorporada para o desperdício mostra que ela ficou entre 7\%-8\% da energia inicial. Isso pode ser associado à falta de planejamento e gerenciamento da construção, à falta de uso de materiais padronizados e até à baixa qualificação da mão de obra (TAVARES, 2006). Logo, para reduzir a energia incorporada deve-se analisar também as perdas dos materiais, otimizando e racionalizando as construções, pois não são gastos apenas recursos financeiros, mas também ambientais.

\section{Conclusão}

A ACVE se mostrou um método eficaz na análise dos sistemas de laje, visto que foi possível quantificar a energia incorporada em suas fases de pré-uso por meio de variáveis significativas. Além disso, esta análise do ciclo de vida permitiu a identificação das etapas e componentes do sistema de maiores impactos ambientais. No entanto, o presente artigo apresenta como limitações a exclusiva avaliação da fase de pré-uso, a não avaliação da energia demandada pela mão de obra e pelos equipamentos durante o estágio de execução e a fixação das distâncias de transporte.

Este estudo apontou que é importante se preocupar não só com as etapas de implantação e execução da obra, mas também com o impacto que os componentes e materiais do sistema causam ao meio ambiente em todas as etapas do seu ciclo de vida, desde a extração e produção até o túmulo.

Analisando os estágios da fase de pré-uso das lajes mistas e maciça, nota-se que para uma mesma condição de contorno as lajes do tipo steel deck apresentam 13\% a mais de energia incorporada em relação às lajes convencionais. Essa constatação era esperada, tendo em vista que o componente principal dessa laje é o aço, produto que consome muita energia desde sua extração da natureza até a sua redução e fabricação da forma final de uso. Vale ressaltar que por mais que o concreto seja o principal item que demande energia nas fases analisadas, este não foi relevante para o cálculo das diferenças de energias entre ambas as lajes por suas quantidades utilizadas serem bem próximas.

Figura 4 - El nos estágios da fase de pré-uso - laje maciça

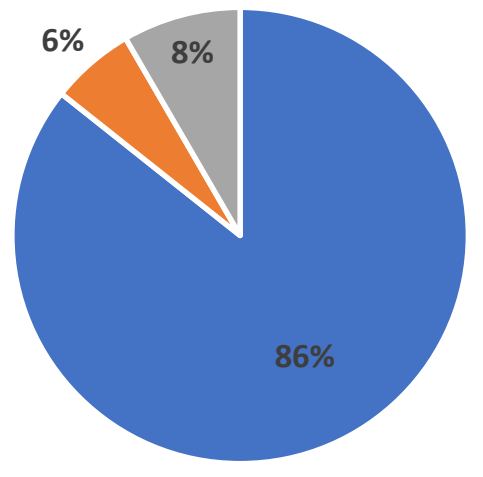

\author{
- El - Extração e \\ Produção \\ - El - Transporte \\ El - Desperdício
}

Figura 5 - El nos estágios da fase de pré-uso - laje steel deck

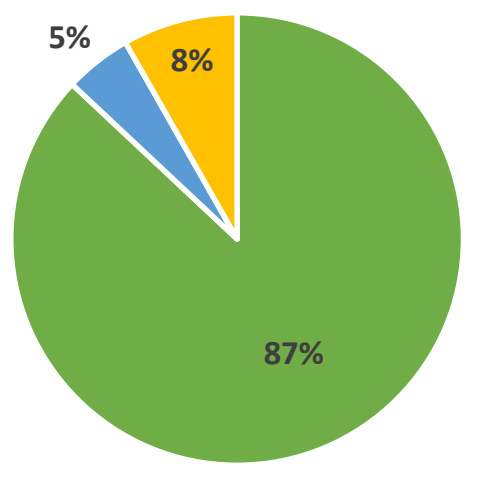

\author{
- El - Extração e \\ Produção \\ - El - Transporte \\ EI - Desperdício
}


Ainda em relação aos estágios do pré-uso, a extração e a produção dos componentes e materiais foram as que mais consumiram energia. Contudo, os transportes e desperdícios devem ser analisados a fim de mitigar os impactos ambientais. Isso porque as distâncias e as cargas impactam na energia e nas emissões de $\mathrm{CO}_{2}$, além do desperdício ainda ser muito elevado nas construções. O desperdício, portanto, deve ser reduzido a partir de métodos mais otimizados e racionalizados, pois seu custo financeiro e ambiental é elevado.

Por fim, este trabalho contribui para estudos futuros de ACVE considerando o inteiro ciclo de vida com a finalidade de analisar quais estágios e fases podem sofrer intervenções para reduzir os impactos ambientais relacionados à energia incorporada. Além disso, permite ver a necessidade de outras análises ambientais, como, por exemplo, a de $\mathrm{ACVCO}_{2}$, em razão de todas as emissões de $\mathrm{CO}_{2}$ que são lançadas na atmosfera em todas as etapas do ciclo de vida dessas estruturas.

\section{Referências}

ALSHAMRANI, O. S. Life Cycle Assessment of Low-Rise Office Building with Different Structure-Envelope. Canadian Journal of Civil Engineering. v. 43. n. 3. p. 193-200, 2015.

AMERICAN SOCIETY FOR TESTING AND MATERIALS. A653: Standard Specification for Steel Sheet, Zinc-Coated (Galvanized) or ZincIron Alloy-Coated (Galvannealed) by the Hot-Dip Process. Geneve, 2018.

\section{ASSOCIAÇÃO BRASILEIRA DE NORMAS} TÉCNICAS. NBR ISO 14040: gestão ambiental: avaliação do ciclo de vida: princípios e estrutura. Rio de Janeiro: ABNT, 2009a.

\section{ASSOCIAÇÃO BRASILEIRA DE NORMAS} TÉCNICAS. NBR ISO 14044: gestão ambiental: avaliação do ciclo de vida: requisitos e orientações. Rio de Janeiro: ABNT, 2009b.

BRUNDTLAND, G. et al. Our Common Future. Oxford e Nova York: Oxford University Press, 1987.

CABEZA, L. F. et al. Life Cycle Assessment (LCA) and Life Cycle Energy Analysis (LCEA) of Buildings and the Building Sector: a review.

Renewable and Sustainable Energy Reviews, v. 29, p. 394-416, 2014.

CASTANHEIRA, L; GOUVEIA, J. B. Energia, Ambiente e Desenvolvimento Sustentável. Porto: Principia, Publicações Universitárias e Científicas, 2004.
CHASTAS, P. et al. Embodied Energy and Nearly Zero Energy Buildings: a review in residential buildings. Procedia Environmental Sciences, v. 38, p. 554-561, 2017.

CHAU, C. K.; LEUNG, T. M.; NG, W. Y. A Review on Life Cycle Assessment, Life Cycle Energy Assessment and Life Cycle Carbon Emissions Assessment on Buildings. Applied Energy, v. 143, n. 1, p. 395-413, 2015.

DIXIT, M. K. Life Cycle Embodied Energy Analysis of Residential Buildings: a review of literature to investigate embodied energy parameters. Renewable and Sustainable Energy Reviews, v. 79, p. 390-413, May 2017.

GOUVEIA, G. M. M. M. Análise EnergéticoAmbiental de Fachadas Com Foco na Reciclagem: estudo de caso com painéis de alumínio composto “ACM” em Brasília. Brasília, 2012. 153 f. Dissertação (Mestrado em Estruturas e Construção Civil) - Departamento de Engenharia Civil e Ambiental, Universidade de Brasília, Brasília, 2012.

LABORATÓRIO DE SUSTENTABILIDADE DA ESCOLA POLITÉCNICA DA UNIVERSIDADE DE SÃO PAULO. Pilares da Sustentabilidade. São Paulo, 2012. Disponível em: $<$ http://lassu.usp.br/sustentabilidade/pilares-dasustentabilidade>. Acesso em: 20 maio 2018.

LIMA, Y. D. C. Alternativas de Sistemas de Lajes Para Edifícios Estruturados em aço: um estudo comparativo. São Paulo, 2009. 119 f. Dissertação (Mestrado em Construção Civil) Universidade Federal de São Carlos, São Paulo, 2009.

LOBO, F.H.R. Inventário de Emissão Equivalente de Dióxido de Carbono e Energia Embutida na Composição de Serviços em Obras Públicas: estudo de caso no estado do Paraná. Curitiba, 2010. 212 f. Dissertação (Mestrado em Estruturas e Construção Civil) Escola de Engenharia, Universidade Federal do Paraná, Curitiba, 2010.

LOTTEAU, M.; LOUBET, P.; SONNEMANN, G. An Analysis to Understand How the Shape of a Concrete Residential Building Influences its Embodied Energy and Embodied Carbon. Energy and Buildings, v. 154, p. 1-11, 2017.

METEFORM. Steel Deck: a solução definitiva em lajes, catálogo. São Paulo, 2017.

MILLER, D.; DOH, J. H.; MULVEY, M.

Concrete Slab Comparison and Embodied Energy Optimisation For Alternate Design and Construction Techniques. Construction and Building Materials, v. 80, p. 329-338, 2015. 
PAULSEN, J. S.; SPOSTO, R. M. A Life Cycle Energy Analysis of Social Housing in Brazil: case study for the program “MY HOUSE MY LIFE”. Energy and Buildings, v. 57, n. 2013, p. 95-102, 2013.

PEDROSO, G. M. Avaliação de Ciclo de Vida Energético (ACVE) de Sistemas de Vedação de Habitações. Brasília, 2015. 226 f. Tese (Doutorado em Estruturas e Construção Civil) Departamento de Engenharia Civil e Ambiental, Universidade de Brasília, Brasília, 2015.

PINI. Tabela de Composições de Preços para Orçamentos. 13. ed. São Paulo: PINI, 2008.

RAUF, A.; CRAWFORD, R. H. Building Service Life and Its Effect on the Life Cycle Embodied Energy of Buildings. Energy, v. 79, n. C, p. 140148, 2015.

REDDY, B. V. V; JAGADISH, K. S. Embodied Energy of Common and Alternative Building Materials and Technologies. Energy and Buildings. v. 35, p. 128-137, 2003.

SABBATINI, F. H. Desenvolvimento de Métodos, Processos e Sistemas Construtivos: formulação e aplicação de uma metodologia. São Paulo, 1989. 336 f. Tese (Doutorado em Engenhria Civil) - Escola Politécnica, Universidade de São Paulo, São Paulo, 1989.
SHARMA, A. et al. Life Cycle Assessment of Buildings: a review. Renewable and Sustainable Energy Reviews, v. 15, n. 1, p. 871-875, 2011.

SILVA, V. G; SILVA, M. G. Seleção de Materiais e Edifícios de Alto Desempenho Ambiental. In: GONÇALVES, J. C. S; BODE, K. Edifício Ambiental. São Paulo: Oficina de Textos, 2015. SPOSTO, R. M.; CALDAS, L. R.; NETO, A. C. N. Energia Incorporada e Emissões de $\mathrm{CO}_{2}$ de Fachadas de Light Steel Framing no Brasil. Oculum Ensaios, v. 13, n. 1, p. 163-182, 2016.

SPOSTO, R. M.; PAULSEN, J. S. Energia Incorporada em Habitações de Interesse Social na Fase de Pré-uso: o caso do Programa Minha Casa Minha Vida no Brasil. Oculum Ensaios, v. 1, p. 39-50, 2014.

TAVARES, S. F. Metodologia de Análise do Ciclo de Vida Energético de Edificações Residenciais Brasileiras. Florianópolis, 2006. Tese (Doutorado em Engenharia Civil) -Escola de Engenharia, Universidade Federal de Santa Catarina, Florianópolis, 2006.

Rachel de Sousa Santos

Departamento de Engenharia Civil e Ambiental, Faculdade de Tecnologia | Universidade de Braślia | Prédio SG 12, Campus Darcy Ribeiro | Brasília - DF - Brasil | CEP 70910900 | Tel.: (61) 98133-0280 | E-mail:eng.rachelsantos@gmail.com

\author{
Revista Ambiente Construído \\ Associação Nacional de Tecnologia do Ambiente Construído \\ Av. Osvaldo Aranha, 99 - 3o andar, Centro \\ Porto Alegre - RS - Brasil \\ CEP $90035-190$ \\ Telefone: +55 (51) 3308-4084 \\ Fax: +55 (51) 3308-4054 \\ www. seer. ufrgs. br/ ambienteconstruido \\ E-mail: ambienteconstruido@ufrgs.br
}

